\section{Shedding of the Penis in Littorina littorea}

SEAsonal resorption of the penis accompanying regression of the testis has been recorded in some dioecious Prosobranch gastropods. Nassarius obsoletus is said to resorb the penis at the end of the breeding season and regenerate it almost immediately ${ }^{1}$; a similar phenomenon has been described in the periwinkle Littorina littorea: the penis is said to become reduced in August and September, perhaps disappearing altogether, ${ }^{2,3}$. This reduction has been described histologically ${ }^{3}$. Reduction of the penis in $L$. littorea during the summer is a well established phenomenon in current literature ${ }^{4}$. In $L$. saxatilis the penis, testes and seminal vesicles have been reported to be much reduced in size during the summer ${ }^{5}$. In $L$. obtusata, however, which breeds all the year round, the penis seems to remain constant in size after sexual maturity is reached (ref. 3 and personal communication from D. Guiterman). This is also the case in the Hawaiian species L. pintado and $L$. picta, where breeding is again continuous ${ }^{6}$.

In an attempt to estimate the fecundity of L. littorea, pairs of copulating animals were placed in $100 \mathrm{ml}$. flasks and kept in the laboratory. The flasks wore supplied with running seawater and the animals fed with Ulva lactuca. Fifteen pairs of animals were isolated in the first 2 weeks of May 1968, and of these ten pairs spawned, four pairs did not spawn and the remaining pair was of two males inadvertently included. During the last week of May and the first week of June, four males from spawning pairs shed the penis. This organ was found in the debris at the bottom of the flask during routine examination for eggs, carried out every $24 \mathrm{~h}$. One individual of the male pair also shed the penis, but the remaining eleven males retained it up to the end of the observations on June 10. Shedding oceurred between 2 and 19 days after cossation of spawning. The coiled testicular duct, or vas deferens, remained white in colour for at least a short period after the shedding of the penis, then became brown.

These observations prompted examination of a shore population to determine whether the penis was shed in the wild. Samples were taken from a rocky shore at Porth Cwyfan, on the south coast of Anglesey, where other work on L. littorea is currently in progress. Animals wore collected and brought back to the laboratory, whore they were killed by scalding with boiling water. Animals were usually killed immediately, but on two occasions they were kept in running, acrated seawater for up to $48 \mathrm{~h}$ before killing. The first sample was taken on June 10 . of forty-five males, thirty-one had a fully developed and functional ponis. Twelve lacked a penis altogether, while two had a fully developed penis loose within the mantlc cavity. On July 3 forty-seven males were collected. Ten of these lacked a penis, twenty-one had a fully developed penis and sixteen had a very minute penis. On July 23 forty-five males were collected, all of which had a minute or small penis, and on July 25 twenty-six more males were collected, of which four lacked a penis, two had a fully developed penis and twenty had a minute or small onc. On August, 6, all the males (about four hundred) in a large routine sample had a small penis. On October 16 the penis was again fully developed, and copulation was observed once in a large sample of animals brought into the laboratory on November 13. Although samples of $L$. littorea have been examined at other times of the year as part of a population study, and always after killing the animals by scalding, only on the occasion mentioned have animals been found with a penis detached within the mantle eavity. Abscission of the penis is therefore not a consequence of scalding. It may be noted that another littoral marine invertebrate, Balanus balanoides, sheds the penis after breeding?

Further work is planned to extend these observations on $L$. littorea in the course of the coming breeding season. In the meantime, it seems safo to say that male $L$. littorea, a.t least on Anglesey shores, shed the penis at the end of the breeding season, rather than resorbing it as was stated to be the case for Irish ${ }^{2}$ and German ${ }^{3}$ populations. Animals kept in the laboratory have been seen to shed the penis, and field collections indicate that the male population passes from the reproductive condition to complete absence of a penis with no intermediate stages which could represent phases of resorption. Furthermore, two animals have been found in June with a detached penis inside the mantle cavity. Shortly after shedding a penis, a new one is grown. It seems either that $L$. littorea males have two rather different patterns of post-reproductive behaviour, or that previous authors have been mistaken in believing that the penis is resorbed. A re-examination of events following breeding in the males of this species is indicated, and perhaps also of male $L$. saxatilis and Nassarius obsoletus which may behave in a similar way.

Marine Science Laboratories, JoHN GRAHAME

Menai Bridge, Anglesey.

Received December 4, 1968.

1 Jenner, C. E., and Chamberiain, N. A., Biol. Bull., Woods Hole, 109, 347 (1955).

2 Tattersall, W. M., Sci. Invest. Fisheries Branch, Dept. Agric. Ireland, 1, 1 (1920).

' Linke, O.,Wiss, Meeresuntersuch., Abt. Uelgoland, 19 (5), 3 (1933).

"Fretter, V., and Graham, A., British Prosobranch Molluses (Ray Society, 1962).

${ }^{5}$ Berry, A. J., J. Anim. Ecol., 30, 27 (1961).

${ }^{6}$ Strubsaker, J. W., Proc. Malac. Soc. Lond., 37, 137 (1966).

${ }^{7}$ Crisp, D. J., and Patcl, B. S., Biol. Bull., Woods Hole, 118, 31 (1960).

\section{Proposed Model Experiments on the Storage of Light Energy in Photosynthesis}

I HAVE proposed ${ }^{1}$ that coherent storage of absorbed light energy in optically non-active modes may be important in photosynthesis. For in this way energy could be transferred to electrons-initiating chemical processes-in steps of more than one quantum of the storage mode. Clearly it would be desirable to devise model experiments that might provide evidenco for the existence of such storage modes. Theoretical conditions for their establish. mont require the excitons excited by light absorption to be strongly scattered in a manner which favours non-linear processes. This suggests the use of amorphous insulating matcrials in the form of microscopic particles deposited on a metal surface and coated with a thin metal layer. If light absorbed in the absorption bands of this material is stored in storage modes, then transfer of more than one storage mode quantum (which has less energy than the light quantum) at a single step should be observable in terms of photoelcetric cmission. From theoretical considerations this should hold at light intensities above a critical value.

It scems relevant in this connexion to comment on recent remarks by $K_{n o x}{ }^{2}$. He scems to think that the high frequency of thermal scattering of excitons constitutes a difficulty for the establishment of a storage mode. Quite on the contrary, however, such scattering represents a necessary requirement for its establishment as I have mentioned. It should also be pointed out that from a logical point of view other difficulties he discusses hold equally for both a non-identified long lived chemical intermediate and a non-identified storage mode-as is seen by replacing in his arguments one expression by the other. Other effects must therefore be established and discussed in order to decide for one or the other, or both or none.

Department of Theoretical Physics,

H. FRÖHLICH

University of Liverpool.

Received January 22, 1969.

${ }^{1}$ Fröhlich, H., Nature, 219, 743 (1968).

${ }^{2}$ Knox, R. S., Nature, 221, 263 (1969). 